\title{
Reflets
}

Revue ontaroise d'intervention sociale et communautaire

\section{Répertoire des organismes de développement économique communautaire du Nord-est de l'Ontario}

\section{Marc Charron}

Volume 5, numéro 1, printemps 1999

Pratiques et développement économique communautaire

URI : https://id.erudit.org/iderudit/026262ar

DOI : https://doi.org/10.7202/026262ar

Aller au sommaire du numéro

Éditeur(s)

Reflets : Revue ontaroise d'intervention sociale et communautaire

ISSN

1203-4576 (imprimé)

1712-8498 (numérique)

Découvrir la revue

Citer ce compte rendu

Charron, M. (1999). Compte rendu de [Répertoire des organismes de

développement économique communautaire du Nord-est de l'Ontario]. Reflets,

5(1), 200-202. https://doi.org/10.7202/026262ar

Tous droits réservés (C) Reflets : Revue ontaroise d'intervention sociale et communautaire, 1999
Ce document est protégé par la loi sur le droit d'auteur. L'utilisation des services d’Érudit (y compris la reproduction) est assujettie à sa politique d'utilisation que vous pouvez consulter en ligne.

https://apropos.erudit.org/fr/usagers/politique-dutilisation/ 


\section{Répertoire des organismes de développement économique communautaire du Nord-est de l'Ontario}

Marc Charron

Chargé de cours, Université Laurentienne

Le thème de "développement économique communautaire» (DÉC) est peu présent dans les écrits de l'Ontario français, bien que sa pratique existe depuis fort longtemps. L'existence du mouvement coopératif Desjardins en Ontario en est une vibrante illustration. Mais au-delà de ce succès phare, on éprouve toujours un certain malaise à identifier les organismes, les entreprises, les associations qui participent à cette mouvance sociale. C'est pourquoi l'existence de ce Répertoire des organismes de développement économique communautaire du Nord-est de l'Ontario vient véritablement combler une lacune en la matière. En établissant un premier repérage des organismes dans le Nord-est de la province, les auteurs, Rachid Bagaoui et Donald Dennie, se sont donné un outil de travail visant à mieux circonscrire cette réalité.

Pour ce faire, les auteurs ont établi une définition de l'approche du développement économique communautaire. S'inspirant des travaux de Louis Favreau qui a balisé le terrain, les auteurs envisagent le DÉC comme une stratégie visant la prise en main par un ou des groupes concernés dans un territoire donné de son propre développement en s'attaquant à toutes les formes de marginalisation socio-économique. Cette stratégie combine les aspects économiques et sociaux du développement et s'oppose ainsi aux approches dites classiques que sont l'entreprise privée, 
mue par la recherche du profit et l'organisation étatique, mue par une logique de pouvoir.

Dans leur avant-propos, les auteurs indiquent les éléments permettant d'établir le profil des organismes: mission, genre de services offerts, clientèle visée, sources de financement, mode de gestion, type de travailleurs, mode de prise de décision, etc. En tout, les auteurs ont recensé trente-quatre (34) organismes ou entreprises dans le Nord-est de la province. On trouvera, dans le répertoire, une description détaillée de chacun.

Parmi les principaux organismes recensés, plusieurs peuvent être regroupés sous le vocable de "corporations de développement économiques communautaires», bien que cette terminologie ne soit pas d'usage courant en Ontario. Ces organismes sans but lucratif favorisent la coordination, la concertation et la solidarité des différents acteurs au sein des communautés concernées en vue de l'amélioration de la situation économique locale (support à la gestion et au financement des entreprises existantes, appui au démarrage de nouvelles entreprises, formation des travailleurs, création locale d'emplois, etc.). On trouve aussi dans le répertoire de nombreuses coopératives d'habitation qui travaillent activement à l'insertion sociale de défavorisés en leur offrant un logement à coût modique.

Certes, les auteurs avouent que ce premier répertoire ne se veut en rien exhaustif. Il s'agit d'un premier jet devant être mis à jour périodiquement et visant à mieux circonscrire une réalité nouvelle, celle d'une prise en main locale afin de combler l'espace laissé vacant par le marché officiel à l'ère de la mondialisation et par l'État à l'ère du désengagement. En se dotant de cet outil, les auteurs avaient également en tête une seconde étape de recherche, celle d'identifier les facteurs de succès qui ont contribué à la longévité de ces organismes. Cette seconde étape réalisée, les auteurs ont l'intention d'animer un débat propre à encourager et susciter cette prise en main locale. 


\section{Note}

On peut se procurer le Répertoire des organismes de développement économique communautaire du Nord-est de l'Ontario auprès de Rachid Bagaoui ou de Donald Dennie, à l'adresse suivante :Département de sociologie, Université Laurentienne, Sudbury, Ontario, P3E 2C6. 